\title{
Roles of antigen receptors and CA215 in the innate immunity of cancer cells
}

\author{
Gregory Lee*, Suefay Liu \\ UBC Center for Reproductive Health, University of British Columbia, Vancouver, Canada; \\ *Corresponding Author: cyglee@yahoo.com
}

Received 26 July 2013; revised 24 August 2013; accepted 8 September 2013

Copyright (C) 2013 Gregory Lee, Suefay Liu. This is an open access article distributed under the Creative Commons Attribution License, which permits unrestricted use, distribution, and reproduction in any medium, provided the original work is properly cited.

\section{ABSTRACT}

Antigen receptors, including immunoglobulins and T-cell receptors, are known to be widely expressed by cancer cells through unconfirmed mechanisms and for unknown purposes. Recently, a monoclonal antibody, designated as RP215, was generated against the ovarian cancer cell line, OC-3-VGH, and was shown to react with CA215, which consisted mainly of these cancer cell-expressed antigen receptors. Experimental evidence has clearly indicated that cancerous immunoglobulins play significant roles in the growth and proliferation of cancer cells in vitro and in vivo. RP215 and anti-antigen receptor antibodies were equally effective in inducing apoptosis and complement-dependent cytotoxicity reactions to cultured cancer cells. Through gene regulation studies, both RP215 and antibodies against antigen-receptors were shown to affect more than a dozen of genes involved in cell proliferation (such as NFKB-1, IgG, $P 21$, cyclin $D 1$, ribosomal $P_{1}$, and c-fos). Furthermore, selected toll-like receptor genes (TLR$2,-3,-4$, and -9 ) were also found to be highly regulated by both RP215 and anti-antigen receptor antibodies. For example, RP215 and antiantigen receptor antibodies were found to both up-regulate TLR-2 and/or TLR-3 and downregulate TLR-4 and TLR-9 in two types of cancer cells. Based on these studies, it is reasonable to postulate that cancerous immunoglobulins play important roles in the modulation of the innate immune system to allow the growth and survival of cancer cells within the human body. Consequently, RP215 in its humanized forms may be

${ }^{*}$ Conflict of interest: Gregory Lee is co-founder of Vancouver BioTech Ltd. The others have nothing to declare. utilized to target cancer cells for potential therapeutic purposes.

Keywords: Antigen Receptors; CA215; Cancer Immunity; Immunoglobulins; Innate Immunity; RP215; T Cell Receptors; Toll-Like Receptors

\section{INTRODUCTION}

Immunoglobulins expressed by cancer cells were initially reported more than a decade ago [1-18]. By use of nested reverse transcription polymerase chain reaction (RT-PCR) on a single cell, it was first observed that the genes of antigen receptors, including those of immunoglobulins and T cell receptors (TCRs), were expressed among several different cancer cell lines $[1,3,5,6,13]$. This phenomenon was initially regarded as spontaneous gene expressions, with little attention paid to its mechanisms or consequences [1]. However, the expressions of cancerous immunoglobulins in almost all cancer cells, tissues, and cell lines, could also be demonstrated through other biological and immunological methods. These methods included immunohistochemical assays, Western blots, in situ hybridizations, and transfection with immunoglobulin-specific small interfering RNA (siRNA) [14]. Following transfections of specific siRNA plasmids, which resulted in down regulation of cancerous immunoglobulin expression, it was found that there was significant growth inhibition of cancer cells both in vitro and in vivo $[3,19]$. Based on these experimental observations, it was proposed that cancerous immunoglobulins were essential for the growth and proliferation of cancer cells. However, little is known regarding the mechanisms of action of these cancerous immunoglobulins, as well as their potential benefit in cancer therapy.

In 1987, RP215 monoclonal antibody (Mab) was initially generated against the OC-3-VGH ovarian cancer cell line and found to react with a carbohydrate-specific 
epitope of CA215 glycoproteins expressed by cancer cells [20,21]. Matrix-assisted laser desorption/ionization time-of-flight mass spectrometry (MALDI-TOF MS) was employed to analyze more than one hundred tryptic peptides from affinity-purified CA215. The majority of the peptide with the RP215-specific "sugar" epitopes was found to consist predominantly of the heavy chains of human immunoglobulins [10]. Furthermore, the RP215specific epitope was also detected in many other CA215 glycoproteins, including TCRs, cell adhesion molecules, and other glycoproteins, with as many as $60 \%$ of these glycoproteins belonging to the immunoglobulin superfamily (IgSF) [22]. Due to the existence of unique and common immunoglobulin-like domains in IgSF proteins, favorable and preferential glycosylation sites may be created, each of which may contain one or more of the RP215-specific "sugar" epitopes [10,23].

Following the discovery of RP215 and its cognate antigen, CA215, many biological and immunological studies were performed [22,24-26]. The major emphasis of these studies has been placed on the roles of cancer cellexpressed antigen receptors and/or CA215 in the growth regulations of cancer cells, as well as the possible mechanisms of action of these antigen receptors and CA215 [22, 27]. The primary gene structures of the detected cancerous immunoglobulins, in particular immunoglobulin $\mathrm{G}$ (IgG), were also determined by established molecular biological techniques [24]. Limited diversifications and variations in the $\mathrm{V}_{\mathrm{H}} \mathrm{DJ}_{\mathrm{H}}$ segments of the heavy chain region in cancerous $\operatorname{IgG}$ were detected in many cancer cell lines and cancerous tissues [14]. This observation marks a significant difference between cancerous IgGs and normal B-cell derived IgGs. Furthermore, strong interactions between cancerous IgGs and toll-like recaptors (TLRs) in the innate immunity of cancer cells were observed through extensive gene regulation studies [28]. These experimental observations seem to suggest that cancerous antigen receptors may play undefined roles in the innate immune system, similar to those of TLRs in cancer cells [29].

Three separate reviews have been published during the last five years regarding the research progress and up-todate knowledge of cancerous immunoglobulins [30-32]. Due to the lack of sufficient experimental evidence, the majority of these reviews only reported the summary of available research results with little definite conclusion regarding the roles and mechanisms of action of these cancerous immunoglobulins. The situation was somewhat improved, when RP215 was identified as a unique probe for further studies of cancerous immunoglobulins [21-25]. However, it later became apparent that CA215 glycoproteins, each of which contained the RP215-specific epitope, consisted of more protein molecules than immunoglobulins. Following extensive biological and im- munological studies of many cancer cell lines, RP215 was found to behave like antibodies against antigen receptors in cancer cells [22]. Therefore, additional progress has been made by using RP215 as the probe in studies of cancer cell-expressed antigen receptors, particularly in determining the mechanisms of action behind these cancerous antigen receptors. During the last decade, many studies have been performed to explore the molecular nature of cancerous immunoglobulins. Although TCRs are also widely expressed among cancer cells, few studies have been reported regarding their roles or actions in the growth regulations of cancer cells, when compared to the functions of $\mathrm{T}$ cells in our normal immune systems $[22,28]$.

In view of these considerations, attempts were made to summarize the recent studies on cancerous immunoglobulins or antigen receptors, as well as to postulate their potential roles in the growth regulations of cancer cells. We believe that a better understanding of cancer immunology can be achieved through an extensive review regarding the roles of antigen receptors and CA215, as well as the innate immunity in cancer cells.

\section{EXPRESSIONS OF IMMUNOGLOBULINS AND CA215 FROM NON-B CELLS}

In a previous review, immunoglobulin expressions in many cancer cell lines and tissues were summarized [32]. With no exceptions, immunoglobulins can be detected in almost all types of cancer cells and cancerous tissues. In addition, the relative ratios of different subclasses of immunoglobulin expressions were found to be similar to those of normal B cell immunoglobulins. By use of semiquantitative RT-PCR analysis, IgG was still found to be the predominant class, followed by immunoglobulin A (IgA) and immunoglobulin M (IgM). Genes that are required for the expressions of immunoglobulins were also detected, including those of recombination activating gene 1 and 2 (RAG1 and RAG2), and activation induced (cytidine) deaminase (AID) in OC-3-VGH ovarian cancer cells [13].

Immunoglobulins expressed by non-B cells were also detected in many normal cells or tissues [3]. Most of the non-B cell-expressed immunoglobulins were found in tissues containing hyperplastic epithelial cells, including those of the skin, esophagus, cervix, and immune privileged sites, such as in the eyes, testis, brain neuron, and placenta [31]. Due to the lack of experimental evidence, the immunoglobulin expressions among these normal tissues could only be explained by the assumption that they may be required for immune protection [17,27,33-39].

The expressions of immunoglobulins were also found to be correlated with cancer cell markers of proliferations 
and cancer stages [17,27,33-39]. A biochemical and immunological analysis was also employed to study the distribution of CA215 which was recognized specifically with RP215. Generally speaking, both cancerous immunoglobulins and CA215 expression were parallel in almost all cancer cells or tissues studied, with few exceptions [13].

\section{MOLECULAR NATURE AND EXPRESSION OF CANCEROUS IMMUNOGLOBULINS}

During the past decade, distinct regulatory mechanisms for the expression of immunoglobulins in cancer cells compared to those of B cells have been demonstrated at the transcriptional, translational and posttranslational levels $(14,32)$. It was initially suggested that cancerous immunoglobulin gene transcripts have distinct $\mathrm{V}_{\mathrm{H}} \mathrm{DJ}_{\mathrm{H}}$ recombination characteristics within human cancer cells. Generally speaking, several established mechanisms are known to generate immunoglobulin diversity in normal B cells, including recombination, and insertion of $\mathrm{V}_{\mathrm{H}}, \mathrm{D}$, and $\mathrm{J}_{\mathrm{H}}$ exons to form the immunoglobulin heavy chains [14,40-43]. Subsequent interactions or activations with antigen result in somatic hypermutation and class switching, as well as generation of greater immunoglobulin diversity. In the case of non-B cells, i.e. either cancer or normal cells, immunoglobulin $\mathrm{V}_{\mathrm{H}}$ genes showed restricted patterns of $\mathrm{V}_{\mathrm{H}} \mathrm{DJ}_{\mathrm{H}}$ combinations [14]. Furthermore, only limited sets of predominant functional $\mathrm{V}_{\mathrm{H}} \mathrm{DJ}_{\mathrm{H}}$ gene recombinations were identified in human cancer cells. Immunoglobulin mutations in cancerous immunoglobulins mainly occur in the framework region III (FWRIII) rather than the complementarity determining region (CDRs), which is atypical for normal $\mathrm{B}$ cell-derived immunoglobulins. This observation may help explain why different cancer cell samples from different individuals expressed immunoglobulins with identical $\mathrm{V}_{\mathrm{H}} \mathrm{DJ}_{\mathrm{H}}$ recombination patterns. In contrast to normal B cell immunoglobulins, cancerous immunoglobulins' $\mathrm{V}_{\mathrm{H} \gamma} \mathrm{DJ}_{\mathrm{H} \gamma}$ variations have limited mutations and are not derived from the same class switching mechanisms [14, 40]. The regulatory mechanisms of cancerous immunoglobulin genes at the transcriptional level were also found to be distinct from those for B cell immunoglobulins. In addition, the promoter used for the expression of cancerous immunoglobulins is distinct from that used for B cell-derived IgG (OCT1 5'-ATGCAAAT-3' vs. OCT-2 in B cells) [40].

At the translational levels, several studies have indicated that cancerous immunoglobulins exhibited identical amino acid sequences $(\geq 99 \%)$ in the heavy chain constant region as B cell-derived immunoglobulins [10]. At the post-translational level, distinct and differential glycosylations of cancerous immunoglobulins were ob- served [10,23]. The RP215-specific epitope was created through post-translational glycosylation on cancerous immunoglobulins. RP215 was the first Mab to react specifically to the carbohydrate-associated epitope in CA215 $[10,22]$, and may be the first example demonstrating a distinction between cancerous immunoglobulins and $\mathrm{B}$ cell immunoglobulins at the post-translational level. Although this "sugar" epitope may also appear in many other CA215-related glycoproteins, more research involving cancerous immunoglobulins can be facilitated through the use of RP215 as a unique probe. At the same time, RP215 may have the potential to be developed as anti-cancer drugs for the therapeutic treatment of cancer in the future [27].

\section{MOLECULAR CHARACTERISTICS OF THE CARBOHYDRATE-ASSOCIATED EPITOPE RECOGNIZED BY RP215 MONOCLONAL ANTIBODY}

Based on the observations of loss of epitope binding activity to RP215 following treatments of CA215 with mild sodium periodate $\left(\mathrm{NaIO}_{4}\right)$, the epitope recognized by RP215 was suggested to be carbohydrate-associated [21]. The RP215-specific epitope can be detected in CA215 from almost all cancer cells. From the shed media of cultured OC-3-VGH ovarian cancer cells, cancerous IgG was affinity-purified sequentially by RP215 and goat anti-human IgG affinity columns, respectively [23]. It was further demonstrated that the O-linked glycan epitope recognized by RP215 is found only in cancerous $\mathrm{IgG}$, but not in normal human IgG [23]. By using goat anti-human IgG as both the capturing and detecting probe, cancerous IgG was shown to exhibit extremely low immunoreactivity when compared to normal $\mathrm{IgG}$. This observation seems to indicate that the immunoreactivity of cancerous IgG may be blocked by the additional glycosylations on cancerous IgG.

Cancerous IgG isolated from affinity-purified CA215 was subjected to glycoanalysis by means of glycopeptide mapping. The primary structure of the RP215-specific "sugar" epitope was further elucidated and tentatively assigned as "GalNAc $\mathrm{Gal}_{1} \mathrm{NeuAc}_{1}$ " or "GalNAc $\mathrm{Gal}_{1}$ $\mathrm{NeuAc}_{2}$ ", preferentially located on the fragment antigenbinding (Fab) regions of cancerous IgG [23]. This "sugar" epitope was considered unique for cancerous IgG, as normal human IgG do not carry this O-linked RP215specific "sugar" epitope [23]. Further structural analysis would be required to obtain the precise linkage structure of the carbohydrate moiety recognized by RP 215 .

The presence of the RP215-specific "sugar" epitope in cancerous IgG can also be demonstrated by RP215-based enzyme immunoassay [23]. Although cancerous IgG is believed to be additionally glycosylated as compared to normal IgG, the binding or functional activity of cancer- 
ous IgG to certain unknown antigens may or may not be affected [44].

\section{RP215 AS THE DIAGNOSTIC TOOL FOR THE STUDY OF CANCER CELL PROLIFERATION, MIGRATION, AND CHEMO-RESISTANCE}

CA215 consists mainly of immunoglobulin heavy chains expressed by cancer cells, each of which contains one or more of the RP215-specific epitope. Therefore, RP215 can be an ideal immune-probe to differentiate between immunoglobulins of B cells and cancer cells for studies of the growth regulations of cancer cells in vitro and in vivo. For example, RP215 can be used independently for monitoring of serum CA215 levels among cancer patients in an enzyme immunoassay kit [24]. At the same time, RP215 can also be used as a diagnostic tool in pathology to investigate the proliferation, migration (metastasis), and chemo-resistance of cancer cells from cancerous tissues. In view of the co-localization of CA215 and cancer stem cell markers, such as CD44 and cytokeratin 5/6 (CK5/6) [45], RP215 can also be used to identify or locate cancer stem cell populations. With RP215 as the immune-probe, several biochemical and immunological techniques including flow cytometry, immunofluorescence assays, cell scratch tests, and methylthiazoletetrazolium (MTT) assays were employed to determine the status of cancer cells. By using RP215 as the specific probe, the relative expressions of immunoglobulins or IgSF proteins in cancer cells, as well as the proliferation status of cancer cells, can be assessed based on the staining intensity of RP215 in immunohistochemical assays. Generally speaking, cancer cells with strong RP215 staining were shown to have a higher degree of migration or growth potential than those with weak staining. Therefore, the former are more resistant to treatments with chemotherapeutic agents such as taxol than the latter $[26,45]$. The results of cell scratch tests seemed to suggest that CA215 with a high degree RP215-specific "sugar" attachments or strong RP215 staining intensity tend to facilitate cancer cells to migrate or metastasize under an in vitro or in vivo environment. Therefore, RP215 can be considered as a useful diagnostic tool for clinical determination of the metastatic status of cancer cells in vivo [26,45].

\section{FUNCTIONAL STUDIES OF ANTI-ANTIGEN RECEPTOR ANTIBODIES AND CA215 ON THE GROWTH AND PROLIFERATION OF CANCER CELLS}

To investigate the roles of cancerous antigen receptors and CA215 in cancer cells, functional assays were per- formed with antibodies against antigen receptors and RP215. Two functional assays were performed to assess the roles of antigen receptors, as well as CA215, on the growth and proliferation of cancer cells. Induced apoptosis and complement-dependent cytotoxicity (CDC) assays were commonly used for these types of in vitro studies $[22,27,46]$.

\subsection{Induced Apoptosis and Nude Mouse Experiments for Functional Assessment}

Antibodies against antigen receptors, as well as RP215, were employed in an in vitro induced apoptosis assay to study their effects on cultured cancer cells [22,23,46,47]. Following 24 to $48 \mathrm{hr}$ incubation of cultured cancer cells with respective antibodies against antigen receptors, or with RP215, induced apoptosis was assessed by the terminal deoxynucleotidyl transferase dUTP nick end labeling (TUNEL) assay. With no exceptions, anti-antigen receptor antibodies and RP215 were shown to induce apoptosis of cultured cancer cell at ligand concentrations of $1-10 \mu \mathrm{g} / \mathrm{mL}$. Results of such comparative analysis are summarized in Figure 1. Furthermore, humanized RP215 was shown to be as effective as RP215 in inducing apoptosis to cultured cancer cells [28]. Similar results of induced apoptosis were obtained with cancer cell lines of many tissue origins, including PC-3 (prostate) and OC-3-VGH (ovary) [27]. Induced apoptosis of cultured cancer cells was also demonstrated with antibodies against immunoglobulin $\mathrm{M}$ ( $\mathrm{IgM})$, immunoglobulin $\mathrm{A}$ (IgA), $\lambda$ light chain, and $\kappa$ light chain. These observations strongly indicate the requirement of different subclasses of cancerous immunoglobulins on the surface of cancer cells for their growth/proliferation, as well as their immune protection.

Consistent with these induced apoptosis results observed in cultured cancer cells, both RP215 and antihuman $\operatorname{IgG}$ were demonstrated to inhibit the growth of implanted tumors in nude mouse experiments with dose-dependency of injected antibodies. The results of these in vivo studies are presented and shown in Tables 1 and 2 with OC-3-VGH ovarian cancer cells and SKMES-1 lung cancer cells as tumor models, respectively. From the data presented in Tables 1 and 2, the dose-dependent reactions of RP215 Mab injections on the volumes of implanted tumors can be demonstrated with significant statistical differences [10,27].

\subsection{Complement-Dependent Cytotoxicity Assay: Treatments of Anti-Antigen Receptor Antibodies and RP215 to Cultured Cancer Cells}

Due to the surface nature of antigen receptors and 
Negative control $\quad \square$ RP215

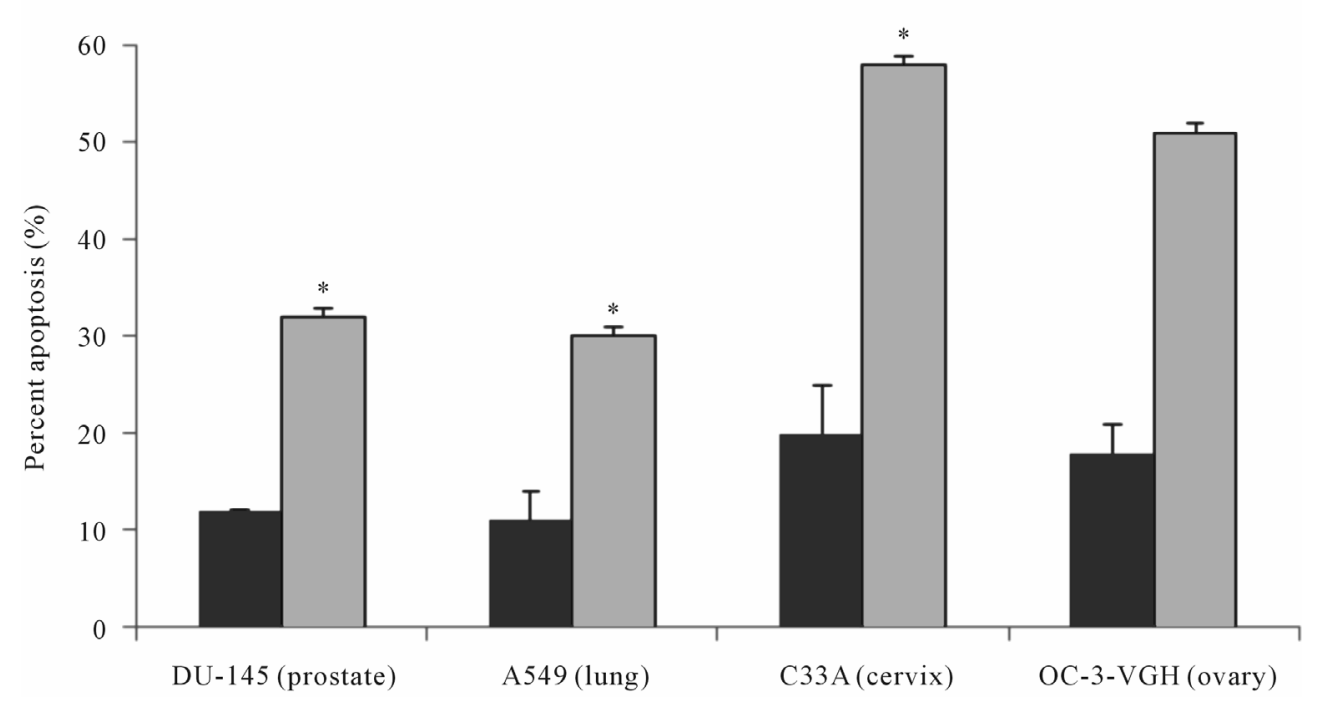

(a)

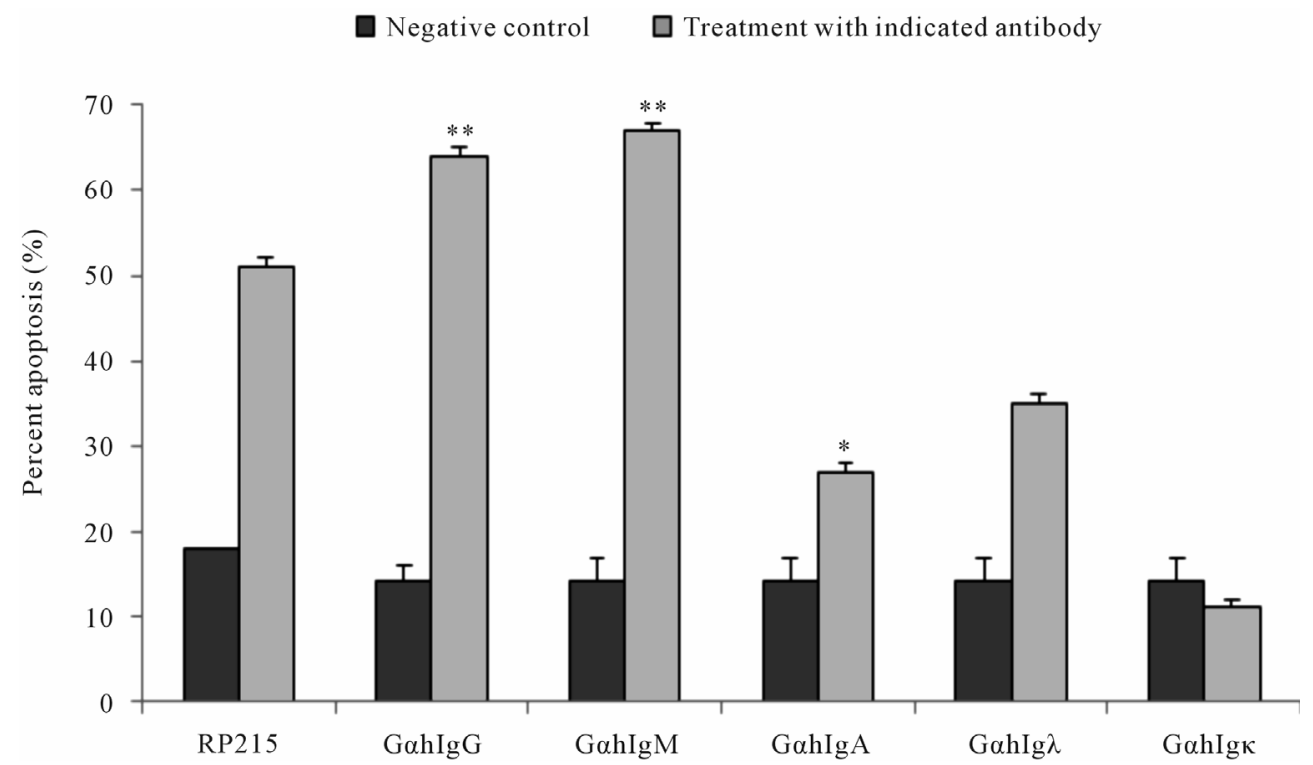

(b)

Figure 1. TUNEL apoptosis assay to demonstrate (a): increase in apoptosis of cultured cancer cells from the prostate (DU-145), lung A549), cervix (C-33A), and ovary (OC-3VGH), respectively, in response to $24 \mathrm{hrs}$ of treatment with $10 \mu \mathrm{g} / \mathrm{mL}$ of RP2 15 with normal mouse IgG serving as the negative control, and (b): increase in apoptosis of cultured OC-3-VGH ovarian cancer cells in response to $24 \mathrm{hrs}$ of treatment with $10 \mu \mathrm{g} / \mathrm{mL}$ of indicated antibodies: goat anti-human IgG (GahIgG), goat anti-

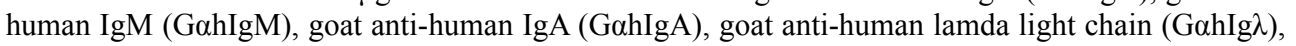

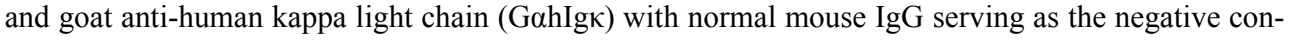
trol. (*) and (**) indicate statistical significance of $\mathrm{P}<0.05$ and $\mathrm{P}<0.01$, respectively. (Obtained and modified from [27] with permission).

CA215 in cancer cells, CDC reactions in cancer cells can be induced upon incubation of any of these ligands in the presence of complement. Results of CDC reaction assays were demonstrated in Figure 2 with different cultured cancer cells. Generally speaking, both antibody-dependent cellular cytotoxicity (ADCC) and $\mathrm{CDC}$ reactions are among the most important effector functions of antibody-based drugs to induce cytotoxicity of cancer cells in vitro or in vivo [27]. Therefore, RP215 may be a suitable alternative for anti-immunoglobulin antibodies with significant anti-cancer efficacy. Based on indications by induced apoptosis and CDC activities, RP215 can be 
Table 1. Results of nude mouse experiments ( $n=4$ for each group) following injection of RP215 on tumour volumes of implanted OC-3-VGH ovarian cancer cells ${ }^{\mathrm{a}}$.

\begin{tabular}{ccc}
\hline Group & Conditions & Tumor volume $\pm \mathrm{SD}^{\mathrm{b}}\left(\mathrm{mm}^{3}\right)$ \\
\hline Negative control & Solvent $\left(\mathrm{H}_{2} \mathrm{O}:\right.$ oil $\left.=1: 1\right)$ & $160.8 \pm 20.1$ \\
Positive control & $60 \mathrm{mg} / \mathrm{kg}$ cyclophosphamide & $92.3 \pm 8.3^{*}$ \\
Antibody high dose & $10 \mathrm{mg} / \mathrm{kg} \mathrm{RP} 215 \mathrm{Mab}$ & $85.5 \pm 1.9^{* *}$ \\
Antibody low dose & $2 \mathrm{mg} / \mathrm{kg} \mathrm{RP} 215 \mathrm{Mab}$ & $113.7 \pm 29.4^{*}$ \\
$\mathrm{I}^{131}$-labeled antibody high dose & $10 \mathrm{mg} / \mathrm{mL} \mathrm{I}^{131}$-labeled RP215 Mab & $47.0 \pm 15.9^{* *}$ \\
$\mathrm{I}^{131}$-labeled antibody medium dose & $5 \mathrm{mg} / \mathrm{mL} \mathrm{I}^{131}$-labeled RP215 Mab & $71.4 \pm 12.4^{* *}$ \\
$\mathrm{I}^{131}$-labeled antibody low dose & $2 \mathrm{mg} / \mathrm{mL} \mathrm{I}^{131}$-labeled RP215 Mab & $136.0 \pm 43.1$ \\
\hline
\end{tabular}

${ }^{\mathrm{a}}$ Protocols for OC-3-VGH with RP215 Mab are described in [27]; ${ }^{\mathrm{b}}$ Volumes were measured on day 16. $\left({ }^{*}\right)$ and $\left({ }^{* *}\right)$ indicate statistical significance of $\mathrm{P}<0.05$ and $\mathrm{P}<0.01$, respectively, in comparison with negative control group. (Obtained and modified from [27] with permission).

Table 2. Results of nude mouse experiments ( $\mathrm{n}=5$ for each group) after injection of RP215 on tumour volumes of implanted SK-MES-1 lung cancer cells ${ }^{\mathrm{a}}$.

\begin{tabular}{ccc}
\hline Group & Condition (dose $/$ mouse) & Tumor volume $\pm \mathrm{SD}^{\mathrm{b}}\left(\mathrm{mm}^{3}\right)$ \\
\hline Negative control & Phosphate-buffered saline & $500.9 \pm 66.0^{* * *}$ \\
Positive control & $\begin{array}{c}\text { Gemcitabine }(\mathrm{GEM})\left(1000 \mathrm{mg} / \mathrm{m}^{2}\right) \\
+ \text { cisplatin }(\mathrm{CDDP})\left(80-100 \mathrm{mg} / \mathrm{m}^{2}\right) / \mathrm{dose}\end{array}$ & $99.26 \pm 28.1^{* * *}$ \\
Antibody high dose & $0.75 \mathrm{mg} /$ dose RP215 Mab & $218.8 \pm 24.0^{* * *}$ \\
Antibody low dose & $0.14 \mathrm{mg} /$ dose RP215 Mab & $276.8 \pm 27.9^{* * *}$
\end{tabular}

${ }^{\mathrm{a}}$ Protocols for SK-MES-1 with treatment of indicated antibodies are described in [27]; ${ }^{\mathrm{b}}$ Tumors were removed and volumes measured after 6 weeks. $\left.{ }^{* * *}\right)$ indicates statistical significance of $\mathrm{P}<0.01$, in comparison with the negative control group. (Obtained and modified from [27] with permission).

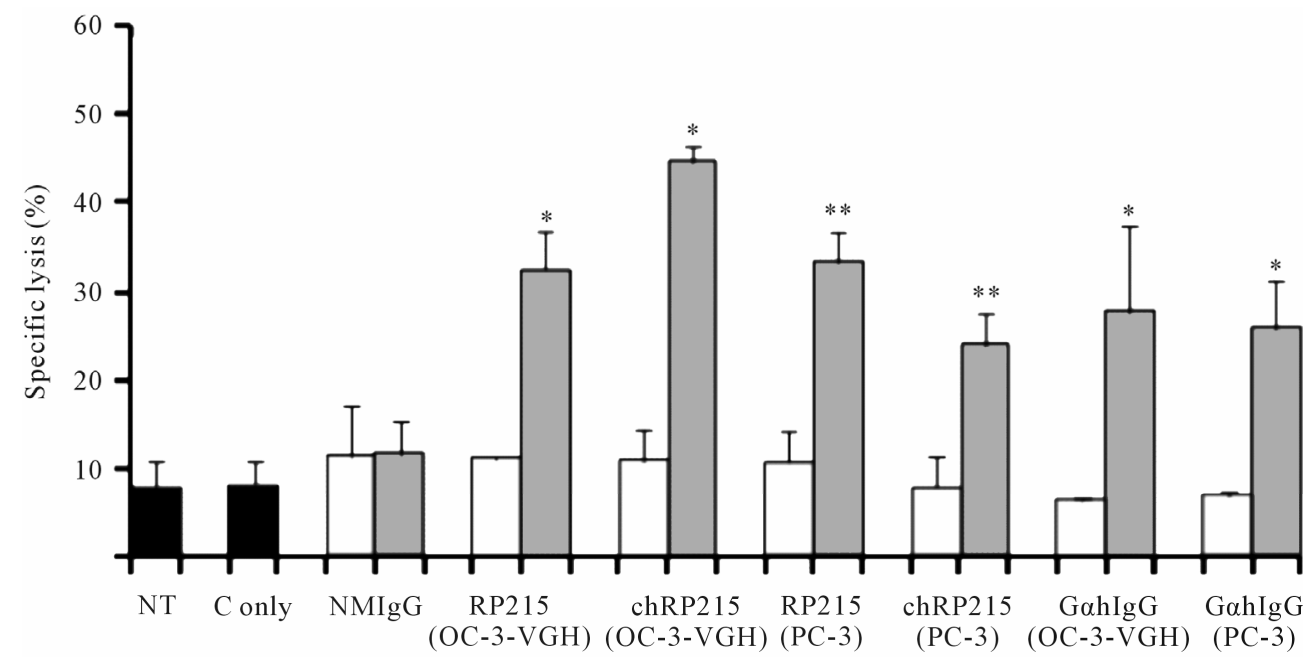

Figure 2. CDC assay to demonstrate the effect of RP215 Mab and its chimeric form (chRP215) on the complement-dependent cell lysis of OC-3-VGH ovarian cancer cells and PC-3 prostate cancer cells. Non-treatment (NT) or $3 \mu \mathrm{L}$ freshly prepared rabbit baby complement (C only) were used as the negative controls (shaded in black). Respective effects of normal mouse IgG (NMIgG), RP215, chimeric form of RP215 (chRP215), and goat anti-human IgG (GahIgG) on either OC-3-VGH ovarian or PC-3 prostate cancer cells (cell line used is indicated in parentheses) are shown. White bars represent the Mab $(10 \mu \mathrm{g} / \mathrm{mL})$ alone while grey bars represent the Mab $(10 \mu \mathrm{g} / \mathrm{mL})$ plus complement. $\left(^{*}\right)$ and $(* *)$ indicate statistical significance of $\mathrm{P}<0.05$ and $\mathrm{P}<0.01$, respectively. (Obtained and modified from [27] with permission). 
developed as a suitable anti-cancer drug [27,46].

\section{GENE REGULATION PATTERNS FOR THE GROWTH INHIBITION OF CANCER CELLS BY ANTI-ANTIGEN RECEPTOR ANTIBODIES OR RP215}

It has been generally accepted that cancerous immunoglobulins are essential for the growth and proliferation of cancer cells, although the mechanism by which cancerous immunoglobulins achieve this remains unknown [3]. In an attempt to elucidate the possible mechanisms of action of these cancerous immunoglobulins, a broad spectrum of gene regulation studies were performed with semi-quantitative RT-PCR. Treatments of OC-3-VGH ovarian and C-33A cervical cancer cells in culture with anti-antigen receptor antibodies or RP215 resulted in dramatic gene regulation changes, which may affect the growth/proliferation or induce apoptosis of cancer cells. Among the genes selected for comparative studies, RP215, anti-human IgG, and anti-TCRs were found to upregulate the genes of nuclear factor kappa-B p105 subunit 1 (NFкB-1), IgG, TCR, cyclin-dependent kinase inhibitor $1(\mathrm{p} 21)$, and ribosomal protein $\mathrm{P}_{1}$. In contrast, downregulations of G1/S phase regulation protein (cyclin D1) and cellular proto-oncogene (c-fos) were consistently observed. Generally speaking, antibodies against IgG, TCRs, and RP215 were found to regulate expressions of these genes consistently with excellent correlation coefficients $\left(R^{2} \geq 0.90-0.94\right)$. These results, as well as those of other genes are displayed in Table 3 with the correlational analysis illustrated in Figure 3 [28].

\section{EFFECTS OF RP215, ANTI-HUMAN IMMUNOGLOBULIN G, AND ANTI-T CELL RECEPTORS ON THE GENE REGULATION OF TOLL-LIKE RECEPTORS}

Since the expressions of cancerous immunoglobulins are distinct from those of $\mathrm{B}$ cell origins, it can be expected that these atypical immunoglobulins may be involved in the innate immunity of cancer cells. Therefore, the effects of anti-antigen receptor antibodies and RP215 on the gene regulations of TLRs, which are essential elements of the innate immune system in cancer cells, were examined. TLRs are known to belong to the family of pattern-recognition receptors (PPRs) which recognize microbe-associated molecular patterns (MAMPs), and play important roles in innate immunity [29,48-51]. In addition, TLRs are also involved in carcinogenesis and in the growth/proliferation of cancer cells [52-59]. Recent studies have demonstrated the expression of TLRs in tumour cells, in addition to their expression in both immune and epithelial cells. These cancerous TLRs are
Table 3. Effects of treatments of cultured OC-3-VGH ovarian cancer cells with different antibodies on the expressions of various genes involved in cell proliferation, protein synthesis, cell cycle regulations, and the innate immunity.

\begin{tabular}{cccc}
\hline \multirow{2}{*}{ Gene $^{\mathrm{a}}$} & \multicolumn{3}{c}{ Antibody $(10 \mu \mathrm{g} / \mathrm{mL})$} \\
\cline { 2 - 4 } & $\begin{array}{c}\text { Goat anti-human } \\
\text { immunoglobulin G }\end{array}$ & $\begin{array}{c}\text { Rabbit anti-T } \\
\text { cell receptor } \beta\end{array}$ & Murine \\
RP215
\end{tabular}

${ }^{a}$ Expressions of genes involved were adjusted with that of glyceraldehyde-3-phosphate dehydrogenase (GAPDH); ${ }^{\text {b }}$ The negative control was normal mouse IgG and was considered $100 \%$ in all cases. (0) less than $10 \%$ gene expression increase or decrease, $(\uparrow) 10 \%-20 \%$ gene expression increase, $(\uparrow \uparrow) 20 \%$ - 30\% gene expression increase, ( $\uparrow \uparrow \uparrow)$ more than $30 \%$ gene expression increase, $(\downarrow) 10 \%-20 \%$ gene expression decrease, $(\downarrow \downarrow)$ $20 \%$ - $30 \%$ gene expression decrease, $(\downarrow \downarrow \downarrow)$ ) more than $30 \%$ gene expression decrease. (Obtained and modified from [28] with permission).

believed to promote both tumor growth and immune evasion through upregulation of NFKB and production of anti-apoptotic molecules [29,60,61]. A variety of cancer cells and cancer cell lines have been shown to express functionally active TLRs, such as TLR-2, -3, -4, and -5 in ovarian cancer $[29,61,62]$, TLR-3, $-4,-5$, and -9 in cervical cancer [61,63-65], TLR-9 in lung cancer [43], TLR-4, -5, -9 in gastric cancer [66], and TLR-2, -3, and -4 in colorectal cancer cells lines [67]. In general, TLR-4 and TLR-9 was found to be most strongly expressed in human cancer cells [32]. However, the endogenous ligand for these cancerous TLRs and the mechanism by which TLRs promote carcinogenesis remains unknown [60].

Detailed analysis was performed regarding the gene expression of selected TLRs upon treatments of cultured cancer cells with anti-antigen receptor antibodies or RP215. The expressions of TLR-4 and TLR-9 genes were downregulated consistently upon treatments with anti-antigen receptor antibodies or RP215, when two different cancer cell lines, namely OC-3-VGH ovarian and C-33A cervical cancer cells, were tested for comparisons. 


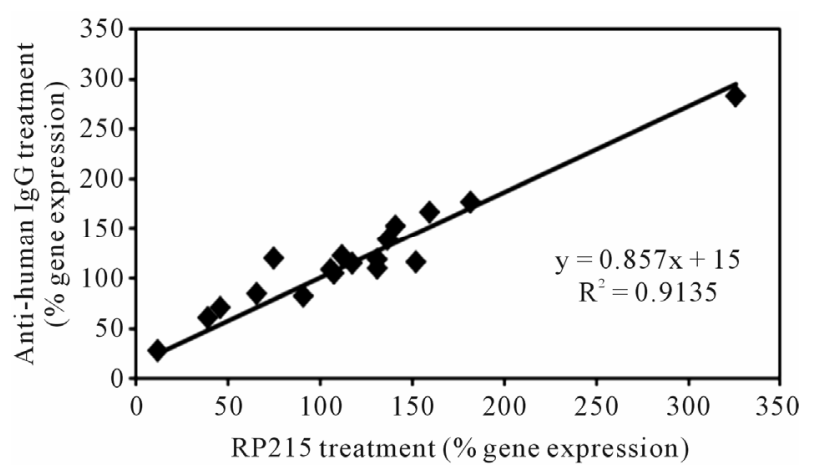

(a)

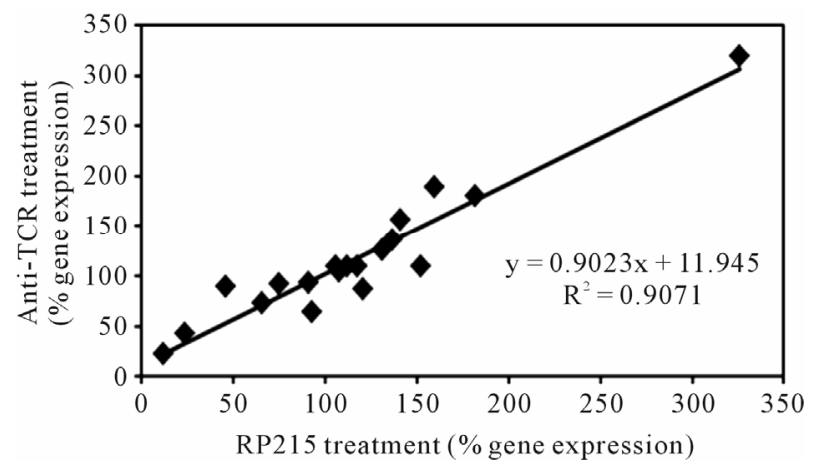

(b)

Figure 3. Correlational analysis of the changes in gene expression levels with different pairs of antibody treatments. Some genes selected for correlational analysis include $\mathrm{IgG}, \mathrm{T}$ cell receptor $\alpha$, NFkB-1, cyclin D1, P21, c-fos, ribosomal proteins $\mathrm{P}_{\mathrm{o}}, \mathrm{P}_{1}$, and $\mathrm{P}_{2}$, epidermal growth-factor receptor, TLR-2, TLR-3, TLR-4, and TLR-9. (a): RP215 and anti-human IgG treatments. (b): RP215 and anti-TCR antibody treatments. The correlation coefficients $\left(\mathrm{R}^{2}\right)$ are 0.9135 and 0.9071 , respectively. (Obtained and modified from [28] with permission).

\section{SPONTANEOUS IMMUNOGLOBULIN M PRODUCTION AND TOLL-LIKE RECEPTORS IN CANCER CELLS}

Many epithelial cancer cells were found to produce IgM, similar to natural IgM produced in B-1 B cells. Secretion of IgM was shown to be increased upon stimulation of TLR-9 which mimics bacterial infection [18]. It was further demonstrated that the expression and secretion of cancer cell-derived IgM is mediated through the TLR-9 myeloid differentiation primary response protein 88 (MyD88) pathway. However, most natural IgM are polyreactive and can bind with low affinity to a number of different antigens prior to the onset of the adaptive immune response [18]. On the other hand, a TLR-4 agonist, such as lipopolysaccharide (LPS), or TLR-4 antagonist, such as naloxone, failed to stimulate changes in the expressions of IgG in cancer cells, indicating unidirectional control of TLRs by IgG [28]. The differential regulations of cancer immunoglobulins such as $\operatorname{IgM}$ and IgG by different TLRs remain to be investigated.

\section{POSSIBLE ROLES OF CANCEROUS IMMUNOGLOBULINS AND TOLL-LIKE RECEPTORS IN THE INNATE IMMUNE SYSTEM}

Significant gene expression changes in selected TLRs, which occur upon bindings to antigen receptors, seem to indirectly support the possible inter-related roles between TLRs and antigen receptors in cancer cells [28]. In addition, similar to anti-antigen receptor antibodies, antibodies against TLR-4 induced apoptosis to cultured cancer cells, suggesting the important role of TLR-4, and possibly of other TLRs, for the survival of cancer cells in vitro or in vivo. While TLR genes were strongly influenced by either anti-antigen receptor antibodies or RP215, antiTLR antibodies were found to have little effect on the expression of cancerous immunoglobulins. This observation suggests that cancerous immunoglobulins exhibit unidirectional control of TLR genes. Furthermore, treatment of OC-3-VGH ovarian cancer cells and C-33A cervical cancer cells with RP215 or anti-antigen receptor antibodies resulted in upregulation of $\mathrm{NF \kappa B}$, which is also activated by the TLR signalling cascade [28]. NFאB is known to be a significant transcription factor involved in the gene regulations/expression of both antigen receptors and TLRs, as well as more than 200 other genes in a variety of biological functions in different cell types [29, 49-51,68-71]. Currently, the exact mechanism by which cancerous immunoglobulins alter TLR gene expression and cause upregulation of $\mathrm{NF \kappa B}$ in cancer cells remains to be elucidated. However, both TLRs and cancerous immunoglobulins have been shown to be required for the growth and survival of cancer cells $[19,72-76]$. Therefore, the expressions of antigen receptors and TLRs in cancer cells may be due to their protective roles in the innate immune system of cancer cells for cancer cell growth and survival.

\section{FUNCTIONAL RELATIONSHIPS BETWEEN ANTIGEN RECEPTORS AND TOLL-LIKE RECEPTORS IN THE INNATE IMMUNITY OF CANCER CELLS}

TLRs were known to be the only receptors in the innate immunity of cancer cells, although cancerous immunoglobulins or antigen receptors may also play parallel roles [77]. For historical and evolutionary reasons, as many as ten TLRs have been identified in human cancer cells, each of which can respond to a specific "antigen" or "pathogen" through conserved microbial structures known as MAMPs, which are common to all microorganisms.

The emergence of cancerous antigen receptors, including cancerous immunoglobulins and TCRs, on the 
cancer cell surface should further enhance the efficacy of immune protection in the innate immunity of cancer cells. Limited and universal expressions of cancerous immunoglobulins indicate that they may be essential for neutralization of undefined endogenous or exogenous "antigens" which are hostile to the growth and proliferation of cancer cells. Currently, the experimental evidence is lacking in regards to the identity of the "antigen" or pathogen" that can be recognized by specific cancerous immunoglobulins. Some progress has been made towards the identification of the endogenous "antigen," of cancerous immunoglobulins through double immunoprecipitation experiments of cancerous immunoglobulins which were followed by sodium dodecyl sulfate polyacrylamide gel electrophoresis (SDS-PAGE) and MALDI-TOF MS. From the preliminary analysis, more than two dozens of proteins have been identified as potential candidates that may interact with cancerous immunoglobulins in vitro or in vivo. Some of these proteins may be involved in the growth/proliferation of cancer cells. Further refinement of this methodology may lead to identification of the "antigen" or "pathogen" targeted by a limited number of cancerous immunoglobulins (Wang and $\mathrm{Gu}$, Shantou University, personal communication).

The involvement of TLRs in the carcinogenesis of cancer cells has been reviewed extensively [29,49-51]. Recently, TLR-related research has greatly advanced and shows promising therapeutic potential against diseases such as inflammation and cancer. It was generally agreed that in cancer cells, TLRs play not only roles in microbial infection, inflammation, and tissue repair, but also in driving tumorigenesis upon stimulation [29,49-51]. Based on these experimental observations, it can be concluded that these TLRs and cancerous immunoglobulins may play similar roles in neutralizing undesirable "antigens/ pathogens" in the innate immune system of cancer cells [28,29,49-51]. Although the "antigens" recognized by cancerous immunoglobulins have yet to be defined and identified, the targeting ligands of these TLRs are known and well established [29]. In addition, strong gene interactions between these two different types of receptors through the regulations of NFKB-1 transcription factor cannot be underestimated. Therefore, blockages or suppression of antigen receptors and/or TLRs of cancer cells should, theoretically, result in growth inhibition of cancer cells. This observation may eventually lead to designing a novel strategy to achieve the objective of cancer therapy.

\section{CONCLUSION}

Although experimental evidence suggests the essential requirement of cancerous immunoglobulins for the growth/proliferation of cancer cells, the molecular mechanisms of action and the relationships to the innate immune system of cancer cells require further investigation. Since the expression repertoire of immunoglobulins from cancer cells is restricted and distinct, only a limited number of these immunoglobulins have been identified among various cancer cells from cells lines or cancerous tissues [14]. Such an expression mechanism is quite different from that of normal B cells which can express an unlimited number of immunoglobulins. Following antigen presentation and/or $\mathrm{T}$ cell activation, diversified immunoglobulins can be produced from mature B cells through the mechanism of somatic hypermutation and class switching [14]. Therefore, it is reasonable to assume that these cancerous immunoglobulins may be produced in a restricted manner for the immune protection of cancer cells under the normal human body environment. Furthermore, the gene interactions between cancerous immunoglobulins and TLRs are highly coordinated. The strong associations between cancerous immunoglobulins and TLRs may also imply the immune protection of cancer cells in vivo. Therefore, the blocking of antigen receptors or TLRs with the appropriate specific antibodies or with RP215 could result in induced apoptosis of cancer cells in vitro or in vivo [28]. This may be one of the important mechanisms of action for the development of RP215 as an anti-cancer drug during cancer therapy in humans.

\section{ACKNOWLEDGEMENTS}

This research project was supported in parts by NRC-IRAP program (\#794354) and the NSERC summer studentship scholarship to Suefay Liu of McGill University. The editorial assistance of Dr. Cheng-Yuan Huang and technical support of Yiting Tang and Hao Zhang are acknowledged.

\section{REFERENCES}

[1] Kimoto, Y. (1998) Expression of heavy-chain constant region of immunoglobulin and T-cell receptor gene transcripts in human non-hematopoietic tumor cell lines. Genes, Chromosomes and Cancer, 22, 83-86.

doi:10.1002/(SICI)1098-2264(1998)22:1<83::AID-GCC1 2>3.0.CO;2-O

[2] Li, J., Tan, C., Xiang, Q., Zhang, X., Ma, J., Wang, J.-R., et al. (2001) Proteomic detection of changes in protein synthesis induced by NGX6 transfected in human nasopharyngeal carcinoma cells. Journal of Protein Chemistry, 20, 265-271. doi:10.1023/A:1010912311564

[3] Qiu, X., Zhu, X., Zhang, L., Mao, Y., Zhang, J., Hao, P., et al. (2003) Human epithelial cancers secrete immunoglobulin $\mathrm{G}$ with unidentified specificity to promote growth and survival of tumor cells. Cancer Research, 63, 64886495.

http://cancerres.aacrjournals.org/content/63/19/6488.abstr act

[4] Li, M., Feng, D.-Y., Ren, W., Zheng, L., Zheng, H., Tang, 
M., et al. (2004) Expression of immunoglobulin kappa light chain constant region in abnormal human cervical epithelial cells. International Journal of Biochemistry and Cell Biology, 36, 2250-2257. doi:10.1016/j.biocel.2004.03.017

[5] Babbage, G., Ottensmeier, C., Blaydes, J., Stevenson, F., and Sahota, S. (2006) Immunoglobulin heavy chain locus events and expression of activation-induced cytidine deaminase in epithelial breast cancer cell lines. Cancer Research, 66, 3996-4000. doi:10.1158/0008-5472.CAN-05-3704

[6] Chen, Z. and Gu, J. (2007) Immunoglobulin G expression in carcinomas and cancer cell lines. FASEB Journal, 21, 2931-2938. doi:10.1096/fj.07-8073com

[7] Zheng, H., Li, M., Liu, H., Ren, W., Hu, D.-S., Shi, Y., et al. (2007) Immunoglobulin alpha heavy chain derived from human epithelial cancer cells promotes the access of $\mathrm{S}$ phase and growth of cancer cells. Cell Biology International, 31, 82-87. doi:10.1016/j.cellbi.2006.09.009

[8] Zheng, H., Li, M., Ren, W., Zeng, L., Liu, H.-D., Hu, D., et al. (2007) Expression and secretion of immunoglobulin alpha heavy chain with diverse VDJ recombinations by human epithelial cancer cells. Molecular Immunology, 44, 2221-2227. doi:10.1016/j.molimm.2006.11.010

[9] Huang, J., Sun, X., Mao, Y., Zhu, X., Zhang, P., Zhang, L., et al. (2008) Expression of immunoglobulin gene with classical V-(D)-J rearrangement in mouse brain neurons. International Journal of Biochemistry and Cell Biology, 40, 1604-1615. doi:10.1016/j.biocel.2007.12.004

[10] Lee, G., Laflamme, E., Chien, C.-H. and Ting, H.H. (2008) Molecular identity of a pan cancer marker, CA215. Cancer Biology and Therapy, 7, 2007-2014. doi:10.4161/cbt.7.12.6984

[11] Zhu, X., Li, C., Sun, X., Mao, Y., Li, G., Liu, X., et al. (2008) Immunoglobulin mRNA and protein expression in human oral epithelial tumor cells. Applied Immunohistochemistry \& Molecular Morphology, 16, 232-238. doi:10.1097/PAI.0b013e31814c915a

[12] Huang, J., Zhang, L., Ma, T., Zhang, P. and Qiu, X. (2009) Expression of immunoglobulin gene with classical V-(D)$\mathrm{J}$ rearrangement in mouse testis and epididymis. Journal of Histochemistry and Cytochemistry, 57, 339-349. doi:10.1369/jhc.2008.951434

[13] Lee, G. and Ge, B. (2009) Cancer cell expressions of immunoglobulin heavy chains with unique carbohydrate-associated biomarker. Cancer Biomarkers, 5, 177-188.

[14] Zheng, J., Huang, J., Mao, Y., Liu, S., Sun, X., Zhu, X., et al. (2009) Immunoglobulin gene transcripts have distinct VHDJH recombination characteristics in human epithelial cancer cells. Journal of Biological Chemistry, 284, 1361013619. doi:10.1074/jbc.M809524200

[15] Zhang, S., Mao, Y., Huang, J., Ma, T., Zhang, L., Zhu, X., et al. (2010) Immunoglobulin gene locus events in epithelial cells of lactating mouse mammary glands. Cellular and Molecular Life Sciences, 67, 985-994. doi:10.1007/s00018-009-0231-z

[16] Hu, D., Duan, Z., Li, M., Jiang, Y., Liu, H., Zheng, H., et al. (2011) Heterogeneity of aberrant immunoglobulin expression in cancer cells. Cellular and Molecular Immu- nology, 8, 479-485. doi:10.1038/cmi.2011.25

[17] Zhang, L., Hu, S., Korteweg, C., Chen, Z., Qiu, Y., Su, M., et al. (2012) Expression of immunoglobulin G in esophageal squamous cell carcinomas and its association with tumor grade and Ki67. Human Pathology, 43, 423434. doi:10.1016/j.humpath.2011.05.020

[18] Hu, F., Zhang, L., Zheng, J., Zhao, L., Huang, J., Shao, W., et al. (2012) Spontaneous production of immunoglobulin $\mathrm{M}$ in human epithelial cancer cells. PLOS ONE, 7, e51423. doi:10.1371/journal.pone.0051423

[19] Li, M., Zheng, H., Duan, Z., Liu, H., Hu, D., Bode, A., et al. (2012) Promotion of cell proliferation and inhibition of ADCC by cancerous immunoglobulin expressed in cancer cell lines. Cellular \& Molecular Immunology, 9, 54-61. doi:10.1038/cmi.2011.40

[20] Lee, C.Y., Chen, K.W., Sheu, F.S., Tsang, A., Chao, K.C., and $\mathrm{Ng}, \mathrm{H} . \mathrm{T}$. (1992) Studies of a tumor-associated antigen, COX-1, recognized by a monoclonal antibody. Cancer Immunology, Immunotherapy, 35, 19-26. doi:10.1007/BF01741050

[21] Lee, G., Wu, Q., Li, C. H., Ting, H.H. and Chien, C.-H. (2006) Recent studies of a new carbohydrate-associated pan cancer marker, CA215. Journal of Clinical Ligand Assay, 29, 47-51. doi:10.4161/cbt.7.12.6984

[22] Lee, G., Zhu, M., Ge, B. and Potzold, S. (2012) Widespread expressions of immunoglobulin superfamily proteins in cancer cells. Cancer Immunology, Immunotherapy, 61, 89-99. doi:10.1007/s00262-011-1088-1

[23] Lee, G. and Azadi P. (2012) Peptide mapping and glycoanalysis of cancer cell-expressed glycoproteins CA215 recognized by RP215 monoclonal antibody. Journal of Carbohydrate Chemistry, 31, 10-30. doi:10.1080/07328303.2011.626544

[24] Lee, G., Ge, B., Huang, T.-K., Zheng, G., Duan, J. and Wang, I.H.Y. (2009) Positive identification of CA215 pan cancer biomarker from serum specimens of cancer patients. Cancer Biomarkers, 6, 111-117.

[25] Lee, G., Zhu, M., Ge, B., Cheung, A. P., Chien, C.-H., Chow, S.-N., et al. (2012) Carbohydrate-associated immunodominant epitope(s) of CA215. Immunological Investigations, 41, 317-336. doi: $10.3109 / 08820139.2011 .633141$

[26] Qiu, X., Liu, W. and Lee, G. (2013) The application of RP215 monoclonal antibody in the study of proliferation, migration, chemo-resistance, of cancer cells as well as cancer stem cells. Chinese Patent No. 201110211923.8.

[27] Lee, G., Cheung, A., Ge, B., Zhu, M., Giolma, B., Li, B., et al. (2012) CA215 and GnRH receptor as targets for cancer therapy. Cancer Immunology, Immunotherapy, 113. doi:10.1007/s00262-012-1230-8

[28] Tang, Y., Zhang, H. and Lee, G. (2013) Similar gene regulation patterns for growth inhibition of cancer cells by RP215 or anti-antigen receptors. Journal of Cancer Science and Therapy, 5, 200-208. doi:10.4172/1948-5956.1000207

[29] So, E.Y. and Ouchi, T. (2010) The application of toll like receptors for cancer therapy. International Journal of Biological Sciences, 6, 675-681. 


\section{doi:10.7150/ijbs.6.675}

[30] Hu, D., Zheng, H., Liu, H., Li, M., Ren, W., Liao, W., et al. (2008) Immunoglobulin expression and its biological significance in cancer cells. Cellular and Molecular Immunology, 5, 319-324. doi:10.1038/cmi.2008.39

[31] Chen, Z., Qiu, X. and Gu, J. (2009) Immunoglobulin expression in non-lymphoid lineage and neoplastic cells. American Journal of Pathology, 174, 1139-1148. doi:10.2353/ajpath.2009.080879

[32] Lee, G. (2012) Cancerous immunoglobulins and CA215: Implications in cancer immunology. American Journal of Immunology, 8, 101-116. http://0.3844/ajisp.2012.101.116

[33] Chen, Z., Huang, X., Ye, J., Pan, P., Cao, Q., Yang, B., et al. (2010) Immunoglobulin $G$ is present in a wide variety of soft tissue tumors and correlates well with proliferation markers and tumor grades. Cancer, 116, 1953-1963. doi:10.1002/cncr.24892

[34] Liu, Y., Chen, Z., Niu, N., Chang, Q., Deng, R., Korteweg, C., et al. (2012) IgG gene expression and its possible significance in prostate cancers. The Prostate, 72, 690-701. doi:10.1002/pros.21476

[35] Niu, N., Zhang, J., Guo, Y., Zhao, Y., Korteweg, C. and $\mathrm{Gu}$, J. (2011) Expression and distribution of immunoglobulin $\mathrm{G}$ and its receptors in the human nervous system. International Journal of Biochemistry and Cell Biology, 43, 556-563. doi:10.1016/j.biocel.2010.12.012

[36] Niu, N., Zhang, J., Huang, T., Sun, Y., Chen, Z., Yi, W., et al. (2012) IgG expression in human colorectal cancer and its relationship to cancer cell behaviors. PLoS One, 7, e47362. doi:10.1371\%2Fjournal.pone.0047362

[37] Niu, N., Zhang, J., Wang, S., Sun, Y., Korteweg, C., Gao, W., et al. (2011) Expression and distribution of immunoglobulin $\mathrm{G}$ and its receptors in an immune privileged site: The eye. Cellular and Molecular Life Sciences, 68, 2481-2492. doi:10.1007/s00018-010-0572-7

[38] Qiu, Y., Korteweg, C., Chen, Z., Li, J., Luo, J., Huang, G., et al. (2012) Immunoglobulin $G$ expression and its colocalization with complement proteins in papillary thyroid cancer. Modern Pathology, 25, 36-45. doi:10.1038/modpathol.2011.139

[39] Zhao, Y., Liu, Y., Chen, Z., Korteweg, C. and Gu, J. (2011) Immunoglobulin $\mathrm{G}$ ( $\mathrm{IgG}$ ) expression in human umbilical cord endothelial cells. Journal of Histochemistry and Cytochemistry, 59, 474-488. http://jhc.sagepub.com/content/59/5/474.abstract

[40] Zhu, X., Wu, L., Zhang, L., Hao, P., Zhang, S., Huang, J., et al. (2010) Distinct regulatory mechanism of immunoglobulin gene transcription in epithelial cancer cells. Cellular Molecular Immunology, 7, 279-286. doi:10.1038/cmi.2010.13

[41] Muramatsu, M., Kinoshita, K., Fagarasan, S., Yamada, S., Shinkai, Y. and Honjo, T. (2000) Class switch recombinetion and hypermutation require activation-induced cytidine deaminase (AID), a potential RNA editing enzyme. Cell, 102, 553-563. doi:10.1016/S0092-8674(00)00078-7

[42] Papavasiliou, F.N. and Schatz, D.G. (2002) Somatic hypermutation of immunoglobulin genes: Merging mecha- nisms for genetic diversity. Cell, 109, S35-S44. doi:10.1016/S0092-8674(02)00706-7

[43] Honjo, T., Kinoshita, K. and Muramatsu M. (2002) Molecular mechanism of class switch recombination: Linkage with somatic hypermutation. Annual Review of Immunology, 20, 165-196.

doi:10.1146/annurev.immunol.20.090501.112049

[44] Lee, G., Cheung, A.P., Li, B., Ge, B. and Chow, P.-M. (2012) Molecular and immuno-characteristics of immunoglobulin-like glycoproteins in cancer cell-expressed biomarker, CA215. Immunological Investigations, 41, 429-446. doi:10.3109/08820139.2012.661007

[45] Chu, P.G. and Weiss, L.M. (2002) Expression of cytokeratin 5/6 in epithelial neoplasms: An immunohistochemical study of 509 cases. Modern Pathology, 15, 6-10. doi:10.1038/modpathol.3880483

[46] Lee, G., Zhu, M. and Ge, B. (2012) Potential monoclonal antibody therapy for the treatment of ovarian cancer. In: Farghaly, S.A., Ed., Ovarian Cancer-Basic Science Perspective, InTech, Vancouver, 385-406. doi:10.5772/27471

[47] Lee, G. and Ge, B. (2010) Inhibition of in vitro tumor cell growth by RP 215 monoclonal antibody and antibodies raised against its anti-idiotype antibodies. Cancer Immunology, Immunotherapy, 59, 1347-1356. doi:10.1007/s00262-010-0864-7

[48] Koropatnick, T.A., Engle, J.T., Apicella, M.A., Stabb, E.V., Goldman, W.E. and McFall-Ngai, M.J. (2004) Microbial factor-mediated development in a host-bacterial mutualism. Science, 306, 1186-1188. doi:10.1126/science. 1102218

[49] O’Neill, L.A.J. (2008) Toll-like receptors in cancer. Oncogene, 27, 158-160. doi:10.1038/sj.onc. 1210903

[50] O’Neill, L.A., Bryant, C.E. and Doyle, S.L. (2009) Therapeutic targeting of toll-like receptors for infectious and inflammatory diseases and cancer. Pharmacological Reviews, 61, 177-197. doi:10.1124/pr.109.001073

[51] Rakoff-Nahoum, S. and Medzhitov, R. (2009) Toll-like receptors and cancer. Nature Reviews. Cancer, 9, 57-63.

[52] Cook, D.N., Pisetsky, D.S. and Schwartz, D.A. (2004) Toll-like receptors in the pathogenesis of human disease. Nature Immunology, 5, 975-979.

[53] Morikawa, T., Sugiyama, A., Kume, H., Ota, S., Kashima, T., Tomita, K., et al. (2007) Identification of toll-like receptor 3 as a potential therapeutic target in clear cell renal cell carcinoma. Clinical Cancer Research, 13, 5703-5709. doi:10.1158/1078-0432.CCR-07-0603

[54] Salaun, B., Lebecque, S., Matikainen, S., Rimoldi, D. and Romero, P. (2007) Toll-like receptor 3 expressed by melanoma cells as a target for therapy? Clinical Cancer Research, 13, 4565-4574. doi:10.1158/1078-0432.CCR-07-0274

[55] Yang, H., Zhou, H., Feng, P., Zhou, X., Wen, H., Xie, X., et al. (2010) Reduced expression of toll-like receptor 4 inhibits human breast cancer cells proliferation and inflammatory cytokines secretion. Journal of Experimental and Clinical Cancer Research, 29, 92. doi:10.1186/1756-9966-29-92

[56] Droemann, D., Albrecht, D., Gerdes, J., Ulmer, A.J., 
Branscheid, D., Vollmer, E., et al. (2005) Human lung cancer cells express functionally active toll-like receptor 9. Respiratory Research, 6, 1 . doi:10.1186/1465-9921-6-1

[57] Ilvesaro, J.M., Merrell, M.A., Swain, T.M., Davidson, J., Zayzafoon, M., Harris, K.W., et al. (2007) Toll like receptor-9 agonists stimulate prostate cancer invasion in vitro. Prostate, 67, 774-781. doi:10.1002/pros.20562

[58] Merrell, M.A., Ilvesaro, J.M., Lehtonen, N., Sorsa, T., Gehrs, B., Rosenthal, E., et al. (2006) Toll-like receptor 9 agonists promote cellular invasion by increasing matrix metalloproteinase activity. Molecular Cancer Research, 4, 437-447. doi:10.1158/1541-7786.MCR-06-0007

[59] Salaun, B., Coste, I., Rissoan, M.C., Lebecque, S.J. and Renno, T. (2006) TLR3 can directly trigger apoptosis in human cancer cells. Journal of Immunology, 176, 48944901. http://www.jimmunol.org/content/176/8/4894

[60] O'Sullivan, T., Saddawi-Konefka, R., Vermi, W., Koebel, C.M., Arthur, C., White, J.M., et al. (2012) Cancer immunoediting by the innate immune system in the absence of adaptive immunity. The Journal of Experimental Medicine, 209, 1869-1882.

doi:10.1084\%2Fjem.20112738

[61] Sato, Y., Goto, Y., Narita, N. and Hoon, D.S. (2009) Cancer cells expressing toll-like receptors and the tumor microenvironment. Cancer Microenvironment, 2, 205-214. doi:10.1007\%2Fs12307-009-0022-y

[62] Lee, J.W., Choi, J.J., Seo, E.S., Kim, M.J., Kim, W.Y., Choi, C.H., et al. (2007) Increased toll-like receptor 9 expression in cervical neoplasia. Molecular Carcinogenesis, 46, 941-947.

[63] Kelly, M.G., Alvero, A.B., Chen, R., Silasi, D.-A., Abrahams, V.M., Chan, S., et al. (2006) TLR-4 signaling promotes tumor growth and paclitaxel chemoresistance in ovarian cancer. Cancer Research, 66, 3859-3868. doi:10.1158/0008-5472.CAN-05-3948

[64] Nishimura, M. and Naito, S. (2005) Tissue-specific mRNA expression profiles of human toll-like receptors and related genes. Biological and Pharmaceutical Bulletin, 28, 886-892. doi:10.1248/bpb.28.886

[65] Kim, W.Y., Lee, J.W., Choi, J.J., Choi, C.H., Kim, T.J., Kim, B.G., et al. (2008) Increased expression of toll-like receptor 5 during progression of cervical neoplasia. International Journal of Gynecological Cancer, 18, 300305. doi:10.1111/j.1525-1438.2007.01008.x

[66] Huang, B., Zhao, J., Li, H., He, K.L., Chen, Y., Chen, S.H., et al. (2005) Toll-like receptors on tumor cells facilitate evasion of immune surveillance. Cancer Research,

\section{5, 5009-5014. doi:10.1158/0008-5472.CAN-05-0784}

[67] Zhou, M., McFarland-Mancini, M.M., Funk, H.M., Husseinzadeh, N., Mounajjed, T. and Drew, A.F. (2009) Toll-like receptor expression in normal ovary and ovarian tumors. Cancer Immunology, Immunotherapy, 58, 13751385. doi:10.1007/s00262-008-0650-y

[68] Li, Q., Withoff, S. and Verma, I.M. (2005) Inflammation-associated cancer: NF-kappaB is the lynchpin. Trends in Immunology, 26, 318-325. doi:10.1016/j.it.2005.04.003

[69] Griffin, J.D. (2001) Leukemia stem cells and constitutive activation of NF-kappaB. Blood, 98, 2291. doi:10.1182/blood.V98.8.2291a

[70] Xie, W., Wang, Y., Huang, Y., Yang, H., Wang, J. and Hu, Z. (2009) Toll-like receptor 2 mediates invasion via activating NF-kappaB in MDA-MB-231 breast cancer cells. Biochemical and Biophysical Research Communications, 379, 1027-1032. doi:10.1016/j.bbrc.2009.01.009

[71] Pikarsky, E., Porat, R.M., Stein, I., Abramovitch, R., Amit, S., Kasem, S., et al. (2004) NF-kappaB functions as a tumour promoter in inflammation-associated cancer. $\mathrm{Na}$ ture, 431, 461-466.

[72] So, E.Y. and Ouchi, T. (2010) The application of toll like receptors for cancer therapy. International Journal of Biological Sciences, 6, 675-681. doi:10.7150/ijbs.6.675

[73] Vesely, M.D., Kershaw, M.H., Schreiber, R.D. and Smyth, M.J. (2011) Natural innate and adaptive immunity to cancer. Annual Review of Immunology, 29, 235-271. doi:10.1146/annurev-immunol-031210-101324

[74] Schmausser, B., Andrulis, M., Endrich, S., Muller-Hermelink, H.K. and Eck, M. (2005) Toll-like receptors TLR4, TLR5 and TLR9 on gastric carcinoma cells: An implication for interaction with Helicobacter pylori. International Journal of Medical Microbiology, 295, 179185. doi:10.1016/j.ijmm.2005.02.009

[75] Furrie, E., Macfarlane, S., Thomson, G. and Macfarlane, G.T. (2005) Toll-like receptors-2, -3 and -4 expression patterns on human colon and their regulation by mucosal-associated bacteria. Immunology, 115, 565-574. doi:10.1111\%2Fj.1365-2567.2005.02200.x

[76] Huang, B., Zhao, J., Unkeless, J.C., Feng, Z.H. and Xiong, H. (2008) TLR signaling by tumor and immune cells: A double-edged sword. Oncogene, 27, 218-224. doi:10.1038/sj.onc.1210904

[77] O’Neill, L.A. (2004) TLRs: Professor Mechnikov, sit on your hat. Trends in Immunology, 25, 687-693. doi:10.1016/j.it.2004.10.005. 